\title{
In Situ Measurements of the Chemical Stability of a Cast Aluminum Alloy Embedded in a Cement Paste with a High Amount of Supplementary Cementitious Material
}

\author{
Ingvild Runningen ${ }^{1, *}$, Ida Westermann ${ }^{1}$, Trond Furu ${ }^{1,2}$ and Harald Justnes ${ }^{1,3} \mathbb{D}$ \\ 1 Department of Materials Science and Engineering, Norwegian University of Science and Technology (NTNU), \\ N-7491 Trondheim, Norway; ida.westermann@ntnu.no (I.W.); trond.furu@hydro.com (T.F.); \\ harald.justnes@sintef.no (H.J.) \\ 2 Norsk Hydro ASA Corporate Technology Office, Drammensveien 260, N-0283 Oslo, Norway \\ 3 SINTEF Community, N-7465 Trondheim, Norway \\ * Correspondence: ingvild.runningen@ntnu.no
}

\section{check for} updates

Citation: Runningen, I.; Westermann, I.; Furu, T.; Justnes, H. In Situ Measurements of the Chemical Stability of a Cast Aluminum Alloy Embedded in a Cement Paste with a High Amount of Supplementary Cementitious Material. Metals 2021, 11, 1441. https://doi.org/10.3390/ met11091441

Academic Editor: Anders E. W. Jarfors

Received: 19 July 2021

Accepted: 7 September 2021

Published: 11 September 2021

Publisher's Note: MDPI stays neutral with regard to jurisdictional claims in published maps and institutional affiliations.

Copyright: (C) 2021 by the authors. Licensee MDPI, Basel, Switzerland. This article is an open access article distributed under the terms and conditions of the Creative Commons Attribution (CC BY) license (https:// creativecommons.org/licenses/by/ $4.0 /)$.

\begin{abstract}
In traditional reinforced concrete, the alkaline pore solution which passivates the steel rebars will get neutralized with time in an exposed environment. Therefore, to prevent corrosion initiation, the permeability of the concrete is reduced and extra-thick concrete covers the steel rebars. Aluminum is passive in the neutralized environment, but the calcium hydroxide formed during the cement hydration will dissolve the aluminum. By substituting $55 \%$ of the cement in traditional cement paste with fast reactive supplementary cementitious material (SCM), aluminum will be compatible over time. In the initial state however, before the SCM consumes the hydroxide formed during the rapid cement hydration by the pozzolanic reaction, aluminum may corrode. Hydrogen gas then develops, resulting in a porous cement region enclosing the rebars with potentially reduced bond strength. In the present work, the chemical stability of a sand-cast aluminum lattice embedded in a paste where cement is replaced by $55 \%$ calcined kaolinitic clay is investigated by gas chromatography and open-circuit potential during the cement hydration. The hydrogen gas development stagnated for all measurements, indicating that aluminum is compatible with the novel cement paste. Two stable potentials were observed for the non-heat-treated samples, indicating the formation of a metastable complex. Being able to use aluminum-reinforced concrete constructions would result in an extraordinary long service life with low cement consumption, which will potentially result in a substantial reduction in the third-largest $\mathrm{CO}_{2}$ emitting industry.
\end{abstract}

Keywords: aluminum; reinforcement; supplementary cementitious materials; gas chromatography; open circuit potential

\section{Introduction}

Concrete is the most used building material in modern times, consisting of aggregate and gravel bound into a solid mass by a hardening cement paste. It is the main component in infrastructure constructions such as bridges and tunnels, dams and highways, and an essential component in buildings, ranging from ordinary houses to skyscrapers.

The concrete industry is the third-largest $\mathrm{CO}_{2}$-emitting industry in the world. Cement clinker, the principal component in cement and thereby concrete constructions, generates approximately one kilogram of carbon dioxide per kilogram produced. Many cements are blended with supplementary cementitious materials (SCMs), and the average clinker content globally is $\sim 75 \%$, but still, cement accounts for more than $90 \%$ of the emissions within the concrete industry [1]. In 2019, the global cement consumption was 4.1 billion metric tons, which accounted for approximately $5-8 \%$ of the global $\mathrm{CO}_{2}$ emissions [2-4].

In addition to the need for new concrete constructions, existing steel-reinforced concrete constructions need maintenance and replacement as they deteriorate over time. The 
deterioration is mainly due to rebar corrosion, as the alkaline pore solution neutralizes by acidic gases like $\mathrm{CO}_{2}$ in the atmosphere and/or aggressive ions like chloride diffuse into the pore solution from the exposed environment with time, depassivating the steel rebars. The depassivation will result in rebar corrosion, with an expanding corrosion product that will promote crack formation in the hardened concrete, accelerating the degradation.

Today, to prevent depassivation of the rebars, the concrete is made with very low permeability, and extra-thick concrete covers the rebars to delay corrosion initiation. This results in a higher strength class than required for the constructions driven by the exposure classes, with a high cement consumption to prevent corrosion, increasing the construction's service life.

Aluminum is passive in neutral environments, unlike steel, but the hydroxide formed during the cement hydration will dissolve the aluminum before the pore solution neutralizes. In the research project Durable Aluminum Reinforced Environmentally-friendly Concrete Construction (DARE2C), which this study is a part of, the aim is to stabilize aluminum with a high amount of calcined clay $(>50 \%)$ replacing cement $[5,6]$. The calcined clay is pozzolanic in nature, meaning that it will consume calcium hydroxide released by the cement hydration and deplete it totally [7]. Cement blends with SCM are quite common, but the cement replacement is restricted to less than $35 \%$ of the cement mass to secure the presence of calcium hydroxide to protect the steel rebars against corrosion in traditional concrete constructions $[8,9]$.

Aluminum will be compatible with this cement paste over time; however, corrosion will occur during the cement hydration before the active hydroxides are removed by the SCM, according to reaction Equation (1). Hydrogen gas then develops, resulting in a porous cement region enclosing the rebars with potentially reduced bond strength [6].

$$
2 \mathrm{Al}_{(\mathrm{s})}+4 \mathrm{H}_{2} \mathrm{O}_{(\mathrm{l})}+2 \mathrm{OH}_{(\mathrm{aq})}^{-} \rightarrow 2 \mathrm{Al}(\mathrm{OH})_{2} \mathrm{O}_{(\mathrm{aq})}^{-}+3 \mathrm{H}_{2(\mathrm{~g})}
$$

By measuring the gas composition as a function of time by gas chromatography (GC) of an aluminum sample embedded in the cement paste during the cement hydration, the hydrogen gas development can indicate active corrosion and further passivation. As the gas chromatograph analyzes the gas composition only, information about the progress of passivation will not be provided. Therefore, by incorporating an open-circuit potential $(\mathrm{OCP})$ measurement in parallel with the GC, this will provide additional information on the progress of corrosion and passivation as a function of time during the cement hydration. The combination of GC and OCP for measuring the hydrogen gas development of aluminum embedded in cement paste has to the authors' knowledge never been published and is considered novel.

One hypothesis is that a metastable aluminosilicate complex may form on the aluminum surface after the dissolution of the oxide film during the cement hydration. The metastable complex may form due to the silicate supply from the SCM in the alkaline solution [10]. The complex could potentially create a film with an inhibiting effect on the aluminum surface, restraining corrosion during the cement hydration [11,12].

As the pore solution will be depleted of active hydroxides, degradation mechanisms such as alkali aggregate reaction (AAR) will not occur, and old concrete constructions could potentially be recycled into new ones. As chlorides will bind, such as Friedel's salt in the cementitious binder formed by the SCM, seawater could potentially be used as a curing agent instead of freshwater, and the constructions would be suited for marine environments. The best hardening accelerator, calcium chloride, can be utilized again as well $[6,13]$.

Aluminum-reinforced concrete construction has the potential to spearhead a new concept of concrete constructions with a low carbon footprint with extraordinarily long service life. As aluminum would be passive in neutral environments, we can allow a higher permeability in the concrete, as well as significantly reduce the thickness of the concrete covers. This, in addition to a high cement substitution, will reduce the cement consumption drastically. The design of concrete constructions can be based on the strength class rather 
than the exposure class. All these factors together would result in a significant reduction in the third-largest $\mathrm{CO}_{2}$ emitting industry [6].

In this work, the chemical stability of a sand-cast aluminum lattice is investigated by measuring the hydrogen gas development in parallel with the OCP during the cement hydration.

\section{Materials and Methods}

This chapter presents the experimental procedure by introducing the sand-cast aluminum lattice, sample selection, and preparation for the chemical stability measurements by GC and OCP in parallel during the cement hydration.

\subsection{Sample Selection from the Sand-Cast Lattice}

Norsk Hydro ASA provided a standard cast ingot of the base material, mimicking a recycled alloy from the automotive industry, which was melted and sand-cast into a lattice as schematically illustrated in Figure 1. A new model-free technique obtained the mold's negative impression, and the lattice used in this project was the first of its kind.

The base material was melted in an electric arc furnace and heated to $753^{\circ} \mathrm{C}$. The melt was then tapped and transported in a preheated crucible where the oxide layer was manually removed before casting. The alloy's castability was good, as excess metal was squeezed out of the drilled holes for air release. The sand mold was manually removed right after casting to reveal the lattice. The lattice had a dimension of $60 \mathrm{~cm} \times 60 \mathrm{~cm}$, with a circle in the center and curved arms connecting the center circle to the surrounding square. The outer surface of the lattice had a degree of surface roughness, resulting from being cast in this sand mold.

Samples from two curved arms of the lattice, with a dimension of $3.3 \mathrm{~cm} \times 1.7 \mathrm{~cm} \times 1 \mathrm{~cm}$, were manually cut out with Struers Labotom-5 (Ballerup, Denmark) with a silicon carbide cut-off wheel. Eight samples were cut out, where one sample from the right arm and one from the left arm had the same condition. The sample selection is presented in Figure 1, where the samples are indexed with numbers, $\mathrm{R}$ presenting surface roughness, and A artificially aged, as listed in Table 1.

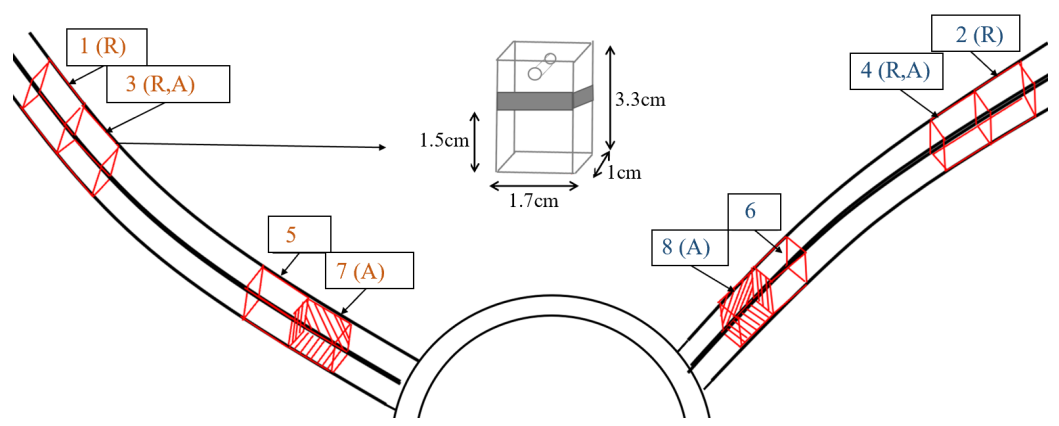

Figure 1. Sample selection from the sand-cast lattice, with a sample dimension of $3.3 \mathrm{~cm} \times 1.7 \mathrm{~cm} \times 1 \mathrm{~cm}$ for the chemical stability measurements. A thin coating line of nitrocellulose in butyl acetate starting $1.5 \mathrm{~cm}$ from the bottom of the samples were incorporated to avoid excess corrosion at the interface.

For half of the samples, the outer surface was manually ground successively with a silicon carbide paper with a FEPA-P grid mesh from 120 to 1200 . These samples are not indexed with an $\mathrm{R}$ as they did not have the surface roughness caused by the sand mold.

Half of the samples were artificially aged, where the purpose of the heat treatment was to grow a thicker oxide film. The supersaturated solid solution heat treatment was conducted in a salt bath holding $525^{\circ} \mathrm{C}$ for $5 \mathrm{~h}$ and water quenched. The samples were further artificially aged in a preheated Nabertherm N15/65HA furnace(Nabertherm GmbH, Lilienthal, Germany) with air circulation holding $180^{\circ} \mathrm{C}$ for $12 \mathrm{~h}$ and water quenched. 
Table 1. The sample conditions for the samples from the left and right arm of the lattice.

\begin{tabular}{ccc}
\hline Condition & Left Arm & Right Arm \\
\hline Surface roughness and no heat treatment & $1(\mathrm{R})$ & $2(\mathrm{R})$ \\
Surface roughness and heat treatment & $3(\mathrm{R}, \mathrm{A})$ & $4(\mathrm{R}, \mathrm{A})$ \\
No surface roughness and no heat treatment & 5 & 6 \\
No surface roughness and heat treatment & $7(\mathrm{~A})$ & $8(\mathrm{~A})$ \\
\hline
\end{tabular}

\subsection{Chemical Stability Measurements}

The samples' chemical stability was investigated in a cement paste where cement was replaced by $55 \%$ calcined kaolinitic clay, by measuring the hydrogen gas development and OCP in parallel during the cement hydration. As the GC analyzed the gas composition, the aluminum sample embedded in the paste was placed within a desiccator to achieve a closed system.

The cement paste mix is listed in Table 2, and the mixing procedure in Table 3 . The cement paste with all additives consisted of 51\% calcined kaolinitic clay from Portugal supplied by Leca International Saint-Gobain Weber located in Avelar, Portugal, as well as $41 \%$ low-alkali sulfate-resistant cement, 5\% gypsum, and 3\% limestone filler by weight supplied by Norcem HeidelbergCement Group, Brevik, Norway. The water to binder ratio was 0.5 .

Table 2. The cement paste composition given in parts by weight with a water to binder ratio of 0.5.

\begin{tabular}{cc}
\hline Component & Amount [Parts by Weight] \\
\hline Water & 0.5 \\
Cement (CEM I) & 0.41 \\
Calcined kaolinitic clay & 0.51 \\
Gypsum & 0.05 \\
Limestone filler & 0.03 \\
\hline
\end{tabular}

Table 3. The procedure for mixing the cement paste, placing the sample, and connecting the GC and OCP.

\begin{tabular}{cc}
\hline Step & Procedure \\
\hline 1. & Pour the water into the high shear mixer bowl. \\
2. & Add dry powder mix. \\
3. & Blend for 1 [min] at max speed. \\
4. & Pour into plastic cup. \\
5. & Place the sample in the sample holder within the plastic lid. \\
6. & Connect the electrochemical measurement. \\
7. & Place the cup in the desiccator. \\
8. & Connect the gas chromatograph. \\
9. & Tamp the cup 10 times. \\
10. &
\end{tabular}

The GC Micro Agilent 490 by Agilent located in California, United States and OCP GRAMRY Reference 600 Potentiostat by GAMRY Instruments located in Philadelphia, United States were connected in parallel, measuring simultaneously during the cement hydration. A hole was drilled at the upper half of the aluminum samples to attach the working electrode clamp. As the sample was partially in air and partially embedded in the cement paste, excess corrosion at the interface was avoided with a thin coating line of nitrocellulose in butyl acetate starting $1.5 \mathrm{~cm}$ from the bottom of the samples, as visualized in Figure 1. The exposed surface area in contact with the cement paste was $10.27 \mathrm{~cm}^{2}$. A 3D printed plastic lid with a sample holder was used to ensure a fixed sample position of the electrodes during the cement hydration. 
In Figure 2 the experimental setup is illustrated, where A, B, C, D, and E presents different parts of the setup.

A: The aluminum sample partly embedded in the cement paste in a plastic cup. Next to the sample was an $\mathrm{Ag} / \mathrm{AgCl}$ electrode, functioning both as a reference and counter electrode. The voltage difference between the electrodes was measured as a function of time during the cement hydration. The blue clamp was attached to the working electrode, and the red and white clamps to the counter and the reference electrode. Further, the sample was placed in the cement paste connected with the clamps for the OCP within the desiccator. In this way, the hydrogen gas that developed during the cement hydration could be measured simultaneously by the gas chromatograph.

B: A pressure gauge for the system. If the inner water column rises, this indicates that the system's pressure rises.

C: The cables from the electrochemical measurement and the GC's outlet of the desiccator. Usually, an airtight glass tube connects the GC to the desiccator, but in this case, cables from the electrochemical measurements also needed a way out. A plastic cork with holes was used, where silicone paste was filled between the wires to minimize the gas leakage.

D: The GC, by Agilent Micro 490, with two columns analyzing the conductivity of lighter and heavier elements.

E: The electrochemical measurement by OCP, by GAMRY Reference 600 Potentiostat.

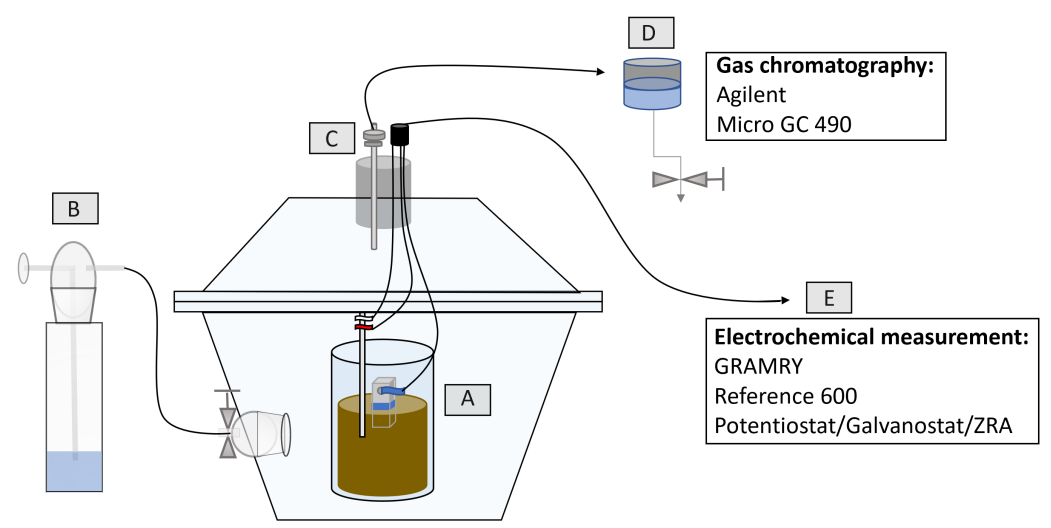

Figure 2. Setup of the GC and OCP measurements in parallel. Point A represents the aluminum sample embedded in the cement paste, connected to the electrochemical measurement within the desiccator. Point B represents the system's pressure gauge, and point $C$ the outlet for the wires for the electrochemical measurement and the gas to be analyzed by the gas chromatograph. Point D represents the Agilent 490 Micro GC, and point E the Reference 600 Potentiostat by GAMRY Instruments, analyzing the gas composition and the OCP during the cement hydration.

\subsubsection{Gas Chromatography}

The operation parameters for the two columns for the gas chromatograph are listed in Table 4. The sampling flow of the micro GC pump was approximately $10-20 \mathrm{~mL} / \mathrm{min}$. The injection interval was $180 \mathrm{~s}$ for the non-heat-treated samples and $300 \mathrm{~s}$ for the heat-treated ones. The different intervals were due to different measuring times, as the chemical stability for the non-heat-treated samples was measured for $24 \mathrm{~h}$ and the heat treated for up to $120 \mathrm{~h}$. 
Table 4. Gas chromatography parameters for column A and B, analyzing the conductivity of lighter and heavier elements.

\begin{tabular}{ccc}
\hline Parameters & Column A & Column B \\
\hline Injector Heating $\left[{ }^{\circ} \mathrm{C}\right]$ & 90 & 65 \\
Column Heating $\left[{ }^{\circ} \mathrm{C}\right]$ & 110 & 70 \\
Injection Time $[\mathrm{ms}]$ & 50 & 50 \\
Backflush Time $[\mathrm{s}]$ & 8 & - \\
Column Pressure [bar] & 1.5 & 1.5 \\
\hline
\end{tabular}

The gas chromatograph was running between each measurement without being connected to the desiccator to remove hydrogen gas residues from the previous measurement.

\subsubsection{Open Circuit Potential}

GAMRY Reference 600 Potentiostat measured the voltage difference between the reference and working electrode during the cement hydration in parallel with the hydrogen gas development. The voltage difference between the electrodes was measured as a function of time during the cement hydration.

The reference and counter electrode was an $\mathrm{Ag} / \mathrm{AgCl}$ electrode. First, an $80 \mathrm{~mm}$ silver wire with a diameter of $1 \mathrm{~mm}$ was ground with silicon carbide paper with grid mesh 500 , to achieve a more reactive surface. It was further cleaned in deionized water before it was dipped for ten seconds in a diluted nitric acid solution and cleaned in deionized water. The counter electrode was a platinum electrode, first cleaned in deionized water before it was dipped and stirred for ten seconds in concentrated sulfuric acid solution and cleaned in deionized water. All chemicals being laboratory grade.

The electrodes were placed in a beaker saturated with sodium chloride. At EC-lab, a blue clamp was attached to the counter electrode $(\mathrm{Pt})$ and the red clamp for the working electrode (Ag). A voltage of 240 microA was applied for $12 \mathrm{~h}$, and a thin layer of white silver chloride coated the silver wire. Due to the coating's light sensitivity, it was kept in the dark until usage. For all the measurements, a new $\mathrm{Ag} / \mathrm{AgCl}$ electrode was made, as the silver chloride layer was destroyed when removing the electrode from the hardened concrete paste by sawing after each measurement.

\section{Results and Discussion}

The samples' chemical stability embedded in a cement paste where cement was replaced by $55 \%$ calcined kaolinitic clay were investigated by GC and OCP during the cement hydration.

Figure 3 presents the hydrogen gas development as a function of time for the different samples embedded in a cement paste with $51 \%$ calcined kaolinitic clay. As the gas chromatograph analyses the hydrogen gas concentration in the desiccator as a function of time, the hydrogen gas development has stopped when the curve flattens out, while the initial slope presents the corrosion rate. As the GC and the OCP were measured in parallel, the system had a small leakage due to the plastic cork, as can be seen, for instance, for measurement 5 in Figure 3; the hydrogen gas concentration decreases with time after the hydrogen gas development has stopped. 


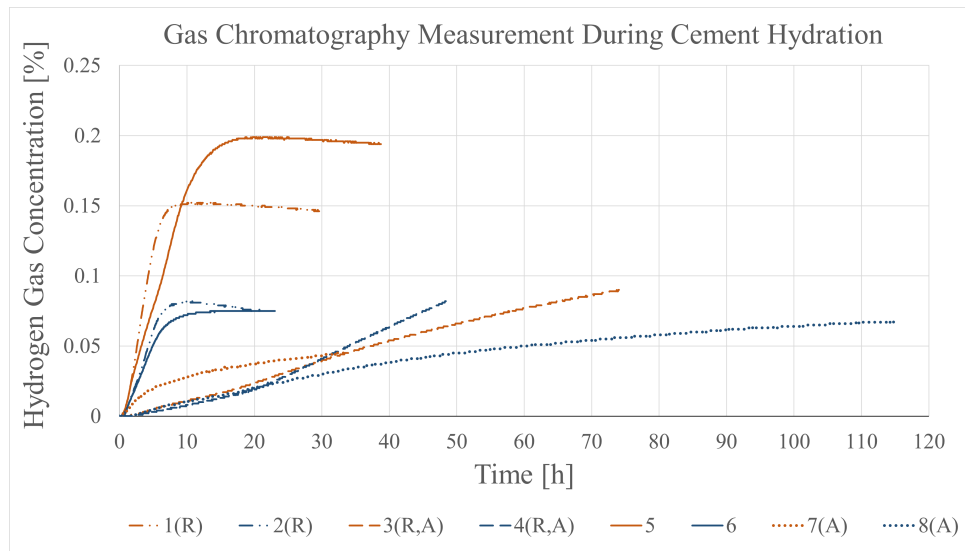

Figure 3. The hydrogen gas development of the aluminum samples embedded in a cement paste with 51\% calcined kaolinitic clay during the cement hydration. The blue curves represent samples from the right arm, and the orange curves samples from the left arm of the lattice. The line style differentiates between the sample conditions.

The blue curves in Figure 3 present the samples from the right arm of the lattice and the orange curves present samples from the left arm, as illustrated in Figure 1. The difference in hydrogen gas development is distinctive for the heat treated, and the non-heat-treated samples, where the non-heat-treated samples have a rapid hydrogen gas development before it stagnates, presented by the solid and (-..-) lines, and the heat treated a prolonged hydrogen gas development with no distinctive stop, presented by (- -) and (...) lines.

The measurements indicate that active corrosion occurs during the cement hydration as hydrogen gas develops. For all measurements, the hydrogen gas development stagnates during the cement hydration, indicating that aluminum is compatible with the cement paste over time [6]. After 28 days, the aluminum cement interface was chiseled open, as presented in Figure 4. As no white corrosion products can be seen at the interface, this indicates that the aluminum sample is compatible with the cement paste.

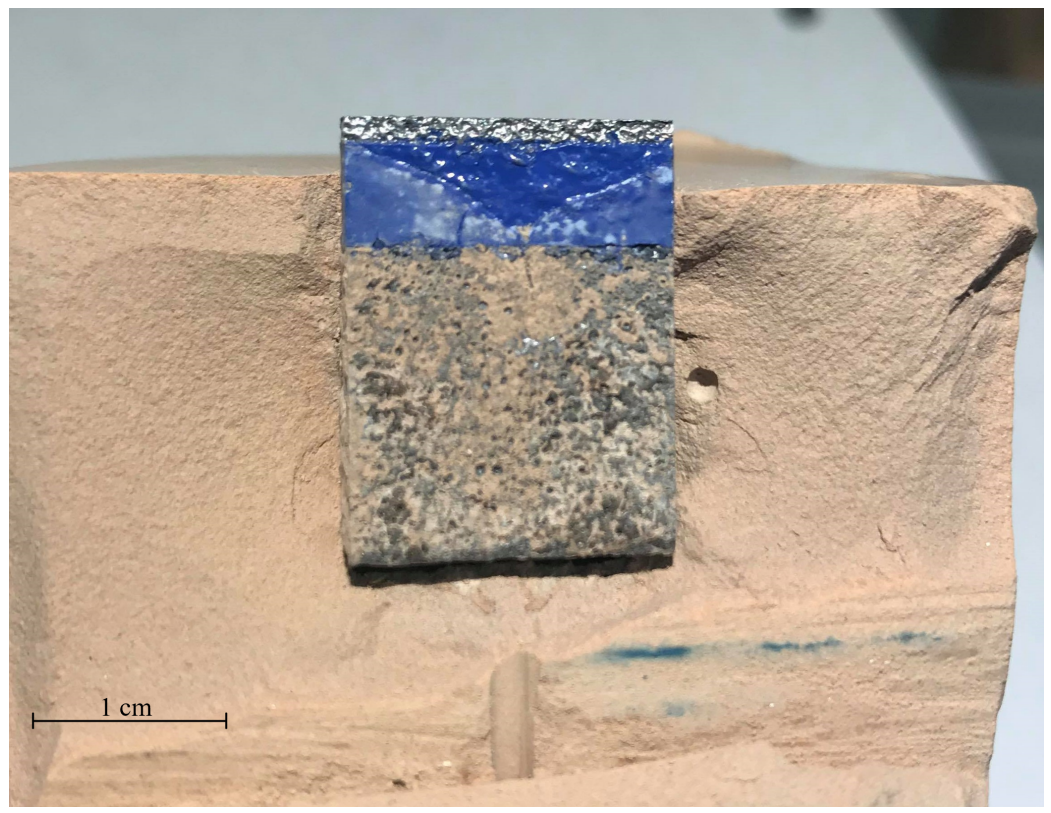

Figure 4. The aluminum cement interface after the aluminum sample has been in the cement paste for 28 days. There is no visual white corrosion product at the interface, indicating that the aluminum sample is compatible with the cement paste. 
For the non-heat-treated samples, the hydrogen gas development differs between the samples from the right and the left arm of the lattice. As the sand mold was manually removed shortly after casting, this could have resulted in different cooling rates for the different arms of the lattice. As the surface roughness was removed for sample 5, the original oxide film formed after casting will not be present, which would have grown due to the isolating effect by the sand mold just after casting. This could have resulted in a less thick oxide film for sample 5 compared to sample 1(R), where sample 5 developed the most hydrogen gas of all the GC measurements presented in Figure 3.

The OCP was measured in parallel with the hydrogen gas development, by measuring the voltage difference between the aluminum sample and an $\mathrm{Ag} / \mathrm{AgCl}$ reference and counter electrode during the cement hydration.

As the reference and counter electrode was an $\mathrm{Ag} / \mathrm{AgCl}$ electrode, this was not perfectly suited for the cement paste's alkaline environment, and there was a chance that it would not work because of that. Other electrodes were also considered, such as graphite and mercury oxide electrodes, but the $\mathrm{Ag} / \mathrm{AgCl}$ electrode was chosen due to time limitations and cost. The OCP measurement for samples $1(\mathrm{R}), 3(\mathrm{R}, \mathrm{A})$, and 5 did not work, as the measurements were not stable, but for those measurements that did work; there were different trends for the OCPs for the non-heat-treated and heat-treated samples, such as for the hydrogen gas development, providing more information about the progress of stabilization as presented in Figure 5.

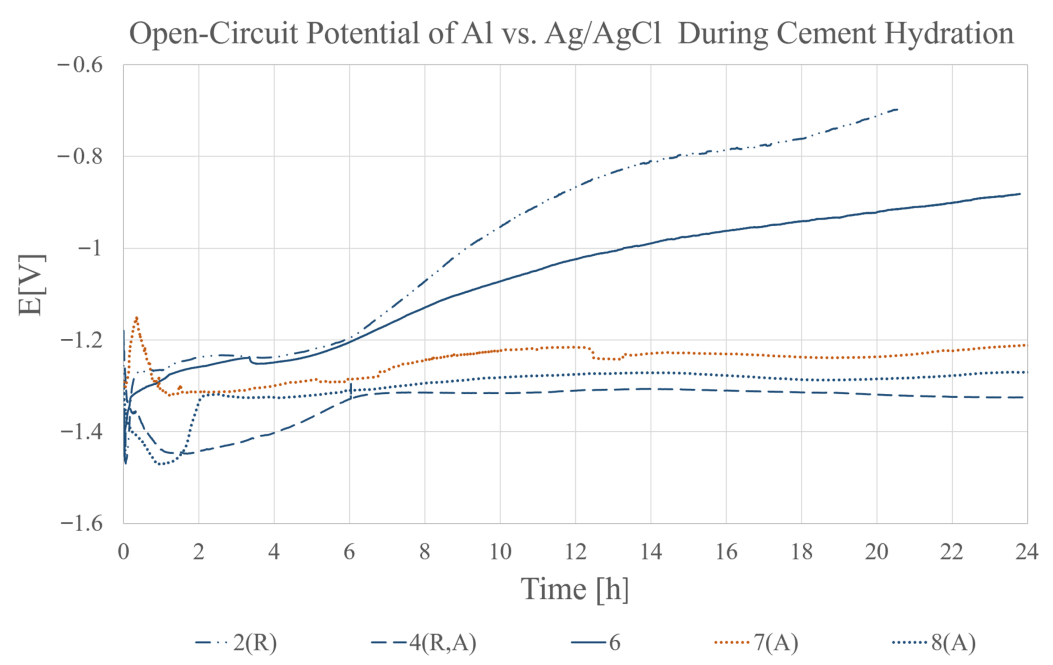

Figure 5. The $\mathrm{OCP}$ between an $\mathrm{Ag} / \mathrm{AgCl}$ reference and counter electrode and the aluminum sample embedded in a cement paste with 51\% calcined kaolinitic clay during the cement hydration. The blue curves represents samples form the right arm and the orange curve sample from the left arm of the lattice. The line style differentiates between the sample conditions.

For the non-heat-treated samples in Figure 5, for measurements 2(R) and 6, the OCP drops immediately before it stabilizes for a time period at approximately $-1250 \mathrm{mV}$. Then, the OCP increases again, and the aluminum becomes nobler before it stabilizes again. The OCP's second stabilization coincides as the hydrogen development stops in Figure 3 at approximately $10 \mathrm{~h}$, as illustrated in Figure 6.

The initial drop indicates that active corrosion takes place during the cement hydration. As two stable potentials were observed after active corrosion, the first stable potential could indicate the formation of a metastable complex. It is possible that a silicate complex forms on the surface, blocking further reaction since there is a huge difference in dissolution rate at $\mathrm{pH}=11.5$ for sodium hydroxide $(>2.5 \mathrm{~mm} /$ year) versus sodium silicate $(<0.1 \mathrm{~mm} /$ year) [12]. The reaction between sodium hydroxide from cement and the calcined clay will supply sodium silicate to the pore water [10]. The start of the second stable potential, might imply the formation of a stable oxide film. This complies with Figure 6, as the hydrogen gas development stopped simultaneously as the second stable 
potential was observed, indicating regeneration of a stable oxide film on the aluminum surface and passivation [11].

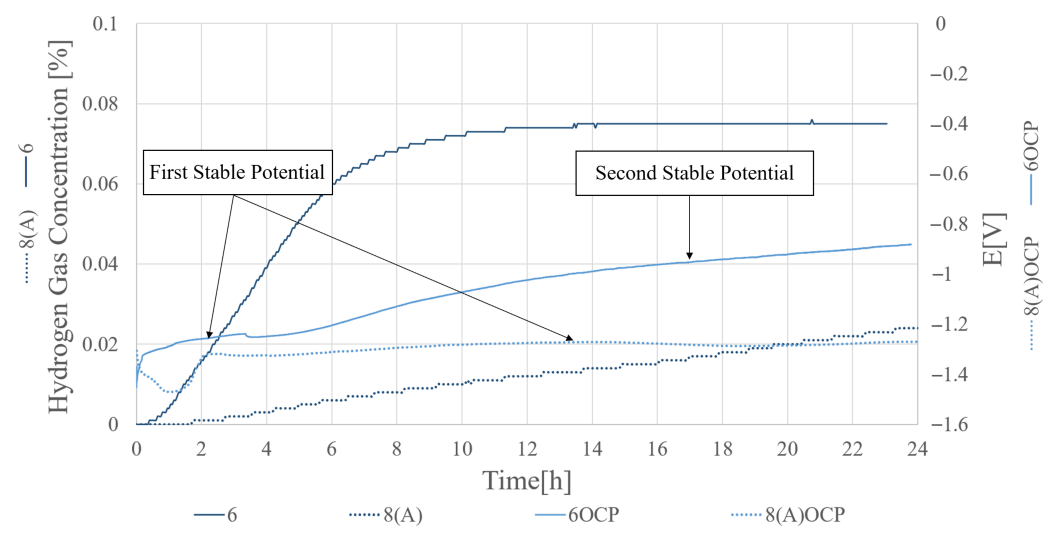

Figure 6. The hydrogen gas development and OCP measured in parallel during the cement hydration of samples 6 and 8(A). Two stable potentials were observed for the non-heat-treated sample 6 , and the first stable potential for the heat-treated sample $8(\mathrm{~A})$.

For the heat-treated samples in Figure 5, measurements $4(\mathrm{R}, \mathrm{A})$ and $8(\mathrm{~A})$ have the same starting trend as the non-heat-treated samples, but the trend was prolonged, and the second stabilization of the OCP does not take place. The stabilization was in accordance with Figure 6, as the heat-treated samples did not have an evident stop in the hydrogen gas development. This could indicate that the metastable complex is more stable and favorable for these samples than for the non-heat-treated ones.

\section{Conclusions}

This study investigates the chemical stability of a sand-cast aluminum lattice in a cement paste where cement is replaced by $55 \%$ calcined kaolinitic clay by measuring the hydrogen gas development and OCP during the cement hydration. The key findings are as follows:

- $\quad$ The hydrogen gas development stagnates for all measurements during the cement hydration, indicating that aluminum is compatible with this cement paste.

- Samples that were artificially aged had a prolonged and reduced hydrogen gas development compared to the non-heat-treated samples.

- Two stable potentials were observed during the cement hydration for the non-heattreated samples. This could indicate the formation of a metastable complex before the regeneration of a stable oxide film during the cement hydration. For the heat-treated samples, the first stable potential was observed, but not the second stabilization. This could indicate that the metastable complex is more stable for the heat-treated samples.

Author Contributions: Conceptualization, H.J.; methodology, I.R.; validation, I.W., T.F. and H.J.; investigation, I.R.; resources, H.J. and T.F.; writing-original draft preparation, I.R.; writing-review and editing, I.R., I.W., T.F. and H.J.; visualization, I.R.; supervision, I.W., T.F. and H.J.; project administration, I.R., I.W., T.F. and H.J.; funding acquisition, DARE2C. All authors have read and agreed to the published version of the manuscript.

Funding: The research in this project has been a part of the Norwegian research project DARE2C with partners Norsk Hydro ASA, NTNU, SINTEF, Norcem AS, Veidekke ASA, and Overhalla Betongbygg AS, with project number no- 269767 funded by the Research Council of Norway.

Institutional Review Board Statement: Not applicable.

Informed Consent Statement: Not applicable.

Data Availability Statement: Not applicable. 
Acknowledgments: I would like to express my gratitude to Heiko Gaertner, and Øyvind Lindgård for their guidance during the chemical stability measurements at SINTEF, and Geir Oshaug, for giving me a warm welcome and insight into the casting industry at Oshaug Metall in Molde.

Conflicts of Interest: The authors declare no conflict of interest.

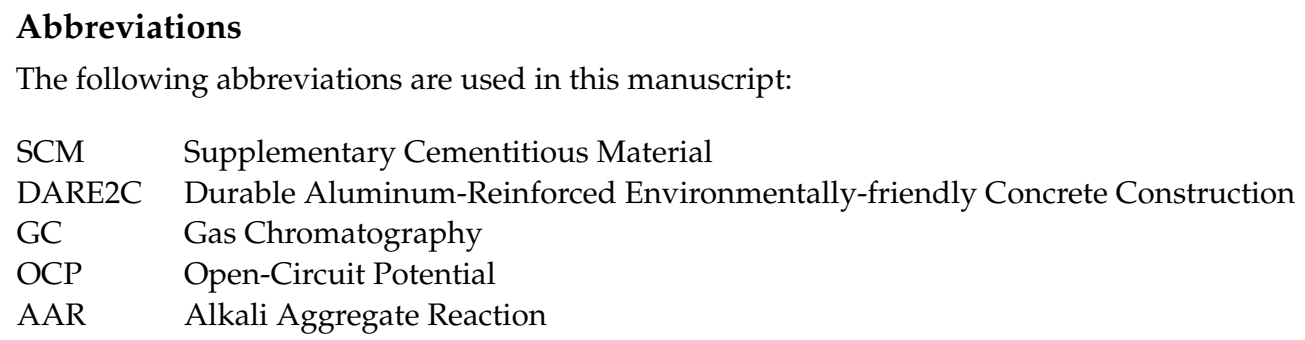

\section{References}

1. Fonta, P. Cement Industry Energy and $\mathrm{CO}_{2}$ Performance- Getting the Numbers Right (GNR); The Cement Sustainability Initiative, World Business Council for Sustainable Development (WBCSD): Geneva, Switzerland, 2016.

2. James, F.; Reilly, II. Mineral Commodity Summaries 2020; U.S. Geologica Survey: Reston, VA, USA 2020; p. 42, ISBN 978-1-41134362-7.

3. Danner, T.; Sletnes, M.; Justnes, H. Alkali-reduced Bauxite Residue as Novel SCM. Nord. Concr. Res. 2020, 63, 1-20. [CrossRef]

4. Lehne, J.; Preston, F. Making Concrete Change Innovation in Low-carbon Cement and Concrete; Chatham House Report; The Royal Institute of International Affairs: London, UK, 2018; ISBN 978-1-78413-272-9.

5. Justnes, H. Concrete Reinforced with Aluminium Metal- Principles and Implication. In Proceeding of the 20th International Conference on Building Materials (ibausil), Weimar, Germany, 12-14 September 2018; pp. 84-95.

6. Justnes, H. Durable Aluminum Reinforced Environmentally-friendly Concrete Construction—DARE2C. Nord. Concr. Res. 2017, $56,71-81$.

7. Danner, T; Norden, G.; Justnes, H. Calcareous smectite clay as a pozzolanic alternative to kaolin. Eur. J. Environ. Civ. Eng. 2019, $23,18$.

8. Justnes, H. Performance of SCMs-Chemical and Physical Principles. In Proceedings of the 2nd International Conference of Sustainable Building Materials (ICSBM2019), Eindhoven, The Netherlands, 12-15 August 2019; ISBN 978-90-386-4898-9.

9. Justnes, H.; Østnor, T.A.; Ng, S. Applicability of Nordic Clays as SCM. In Proceedings of the International RILEM Conference on Materials, Systems and Structures in Civil Engineering, Conference Segment on Concrete with Supplementary Cementitious Materials, Lyngby, Denmark, 22-14 August 2016; RILEM Proceedings 113; Technical University of Denmark: Lyngby, Denmark, 2016; pp. 331-340. ISBN 978-2-35158-178-0.

10. Danner, T. Reactivity of Calcined Clays. Ph.D. Thesis, Norwegian University of Science and Technology (NTNU), Trondheim, Norway, 2013; p. 229.

11. Vargel, C. Corrosion of Aluminium; Part B. Corrosion of Aluminium; Elsevier: Amsterdam, The Netherlands, $2004 ;$ pp. 81-230.

12. Davis, J.R. Corrosion of Aluminum and Aluminum Alloys; Chapter 2: Understanding the Corrosion Behaviour of Aluminum; The Materials Information Society: Materials Park, OH, USA, 1999.

13. Justnes, H. Aluminium Metal Reinforced Concrete-An Environmentally Friendly System with Infinite Service Life. ICJ Indian Concr. J. 2020, 94, 68-73. 